\title{
CONTROLLING NEW PRODUCTS: A CONTINGENCY APPROACH
}

by

\author{
Christopher K. Bart, Ph.D., C.A. \\ Associate Professor of Business Policy \\ Michael G. DeGroote School of Business \\ McMaster University \\ Hamilton, Ontario Canada L8S 4M4
}

Innovation Research Working Group

WORKING PAPER NO. 35

February 1995

\begin{abstract}
The Working Paper series is intended as a means whereby a researcher may communicate his or her thoughts and findings to interested readers for their comments. The paper should be considered preliminary in nature and may require substantial revision. Accordingly, this Working Paper should not be quoted nor the data referred to without the written consent of the author. Your comments and suggestions are welcome and should be directed to the author.
\end{abstract}

\section{Innis}

HD

45

. 1657

no. 35 
Controlling New Products: A Contingency Approach

by

Christopher K. Bart, Ph.D., C.A. Associate Professor of Business Policy Michael G. DeGroote School of Business McMaster University

Hamilton, Ontario, Canada, L8S-4M4

Voice mail: (905) 525-9140 ext. 2-3967

Fax mail: (905) 527-0100

E-mail: bartck@mcmaster,ca

((c)) 1995, Christopher K. Bart 


\title{
Controlling New Products: A Contingency Approach
}

\begin{abstract}
This article presents the findings from a large sample investigation into the way that SBU managers in large companies control different types of new products. The study also reports on the impact that different control choices have on two performance outcomes: new product output and new product success. The findings indicate that, consistent with the tenets of contingency theory, different new product strategies require different control approaches on the part of SBU managers and that an SBU manager's choice of controls matters in terms of performance. Most importantly, though, the findings underscore the balance and trade-offs that SBU managers may have to make in the course of pursuing different performance objectives.
\end{abstract}




\section{Controlling New Products: A Contingency Approach}

Are there differences in the way that large firms control their different types of new products? And, if so, do these variations make a difference in terms of firm performance?

Until recently, few researchers have suggested that differences might exit (and be appropriate) in the way that managers control different types of new products. In fact, most previous writers and researchers have suggested that all new products should be managed in much the same manner i.e. significantly looser than existing products (Burns \& Stalker, 1961; Aiken \& Hage, 1979; Hage \& Aiken, 1967; Lawrence \& Lorsch, 1967; Galbraith \& Kazanjian, 1986; Peters \& Waterman, 1983).

Bart (1991), however, has suggested that earlier distinctions for managing new products are too simple because all new products are not the same. Yet, little is still known about the specific control practices that managers use with respect to different types of new products. There is a paucity of studies comparing the control practices of different types of new products directly. Even less is known about whether the differences in control practices affect performance in any significant manner. And most writings have tended to be either highly anecdotal in nature or very limited sample sizes.

This study is built upon previous work that tested the relationship between a firm's new product strategy, managerial control practices and performance (i.e. frequency of new product output). It focusses on developing and testing a contingency perspective in which implementation of different managerial controls is related to different strategic conditions under different performance measures - namely, new product output and new product success. 
Using a typology developed by Bart (1991, 1993a, 1993b), this study investigates managerial control practices under two different categories of new products: familiarity and uniqueness. Our central propositions state that (a) managerial control choices depend on which type of new product is being managed and (b) how managers control new products influences firm performance.

\section{THEORY AND HYPOTHESES}

Previous research has established that organizational control arrangements must be congruent with strategy if a firm is to realize the economic benefits associated with that strategy (Hill \& Hoskisson, 1987). For the most part, the focus of prior strategy-structure research has been primarily on corporate-level strategies and on equally general aspects of organizational control (Bart, 1986). The relationship between control and different stages (or degrees) of diversification, however, appears to have received an inordinate amount of attention (Chandler, 1962; Rumelt, 1974; Lorsch \& Allen, 1973; Hoskisson, 1987; Hoskisson \& Hitt, 1988; Baysinger \& Hoskisson, 1989). Other types of strategies have not received the same degree of consideration and scrutinization.

In particular, the relationship between organizational control and product innovation is a management topic that remains both under-emphasized and under-researched (Evan, 1976; Kimberley, 1981; Klavans et al, 1985; Williamson, 1980; Bart, 1991). To date, only Bart (1986, 1991, 1993a, 1993b) has conducted any empirical studies which have examined specifically for variations in numerous organizational control arrangements that might accompany different 
product-level strategies. In addition, while "organizing for innovation" has received considerable research attention, "organizing for different types of innovation" has not. As a result, the development of innovation theory as it applies to new products in large firms has not progressed very much and our knowledge remains somewhat limited (Downs \& Mohr, 1976; Ettlie et al, 1984; Bart, 1991). The historical research base on the control requirements for managing new products, however, is especially narrow. Because of this, we have been forced, at times, to borrow some key notions from the literature on diversification in the development of some of our hypotheses.

\section{New Product Familiarity}

New products can either be "related" to a firm's existing product line or "unrelated". When a new product is developed which is related, the firm is seeking to capitalize on an existing resource or competence (Hoskisson, 1987) or to exploit economies of scope (Teese, 1982). Where an organization pursues new products that have no connection to existing skills or resources, the strategy is considered to be unrelated in nature (Rumelt, 1972; Hoskisson, 1987; Bart, 1991, 1993a, 1993b).

There is considerable controversy in the literature as to the appropriate degree of control that senior managers should exercise over their related and unrelated enterprises and initiatives. On the one hand there are those who feel that unrelated products should be managed much more tightly than related products. Souder (1987), for example, found that high levels of formal and informal communication between lower and upper-level managers and high amounts of top management support were especially important in managing unrelated new products. Norman 
(1971) has also claimed that with increased unrelatedness of new products, there is a significant increase in top management involvement.

Interestingly, when Bart (1990, 1993a, 1993b) examined specific new product control practices and compared them to those used for "established" products, he found many significant differences between related and unrelated new product situations. He could find, however, no significant difference in the "overall degree of control" exercised by senior managers. Nevertheless, it was his impression that senior managers appeared to exercise "tighter" overall control for their unrelated new products and "looser" overall control for their related ones.

In the case of related new products, one senior divisional manager explained his lack of involvement to Bart (1993a) as follows:

"Those subordinates reporting to me with related new products already have the knowledge and skills required to manage the product without my becoming heavily involved. I can feel secure about giving them room to manoeuvre because I'm able to judge their activities from a distance and with only occasional monitoring and interaction. After all, because of the nature of the product, we can all easily relate to it." (p.353)

On the other hand, when senior managers are unfamiliar with their new products' technology and/or markets, Bart suggested that they increase their involvement in order to getto-know the intricacies of their new products and hopefully to exploit any emergent synergies within their existing divisions or operations.

All of Bart's studies, however, have been plagued with relatively small sample sizes. Moreover, he did not systematically compare either the control practices or performance characteristics of different new product strategies directly. Instead, he compared the control practices of selected new products with those used to manage "existing" products only.

Another point of view. In contrast to the opinions expressed above, the diversification 
literature has established that highly successful firms practice unrelated diversification with a system of controls which is significantly looser and much more impersonal than that used for related type diversifications (Lorsch \& Allen, 1973; Dundas \& Richardson, 1982; Hoskisson, 1987; Baysinger \& Hoskisson, 1989). This type of control occurs because senior managers have limited information process ing capabilities and because they lack detailed operating knowledge of their unrelated divisions. As a consequence, they delegate many more operational matters to their divisional managers and exercise control through the financial reporting system only. (Firms that perform poorly, on the other hand, tend to have senior managers who spend too much time trying to integrate their unrelated divisional operations and not enough effort on acting like holding companies.)

Conversely, the diversification literature argues that realizing the economies of scope that accrue from related-type acquisitions requires considerable coordination among divisions (Hoskisson, 1987). In such instances, corporate level managers, however, usually have some depth of knowledge regarding operations in order to assure that synergy among related divisions is pursued. Hence, control over related divisions tends to be "tight" or "high". Hoskisson, however, cautions:

"Synergy does not develop among decentralized operating divisions unless a corporatelevel process finds opportunities for cooperation between potentially interrelated divisions. Such a process requires centralized information flows so that corporate managers can identify opportunities for the synergistic extension of ideas developed in one division that may have applications in other divisions. Even if interdivisional task forces are employed, corporate or SBU-level executives must monitor the process to allocate resources appropriately. Thus, either at the corporate or the group level, top managers must understand operational and strategic issues to achieve economies of scope" (p.630-631).

Hoskisson then hypothesized and later confirmed that those related-diversified firms that 
operated with loose controls would experience only modest increases (as opposed to significant increases) in efficiency.

Interestingly, in a study of performance differences between "related-diversifieds", Rumelt found no performance differences between firms in which decision making was highly centralized and tightly controlled (i.e. functionally structured firms where senior managers were highly involved in operations) and those where they were not (i.e. product divisions where senior managers were not involved in operations). Thus, further research appears to be warranted.

Because we could not specify in advance the direction that a difference in "overall control" would take, we developed the following hypothesis:

H1: The overall degree of control exercised by senior managers will vary significantly between internally developed related and unrelated new products.

The diversification literature, however, provides some potential clues as to how the nature of control might vary between related and unrelated situations. Generally speaking, managerial control mechanisms can de divided into two broad groupings: formal and informal. Formal controls are sometimes referred to as financial, tangible, bureaucratic, output or formal controls. They typically represent those written goals, rules, policies, procedures and systems found within a firm (Bart, 1993b). Informal controls are sometimes referred to as strategic, intangible, clan, or behavioral controls. This type of control emphasizes personal contact and interpersonal interaction; unwritten objectives, rules, information, procedures and systems; and the latitude/discretion in decision making (i.e. autonomy) that a superior gives a subordinate (Bart 1993b). 
Within the diversification literature, it is generally agreed that formal-type controls are significantly tighter for unrelated divisions than they are for related type ones (Baysinger \& Hoskisson, 1989; Hoskisson \& Hitt, 1988; Hoskisson, 1987; Gupta, 1987; Williamson, 1975). It is also a general conclusion that informal-type controls are significantly tighter in the case of related divisions. This pattern of control exists, once again, largely because of the information processing capabilities and requirements of senior managers.

We decided, therefore, to adapt these findings from the diversification literature for the purpose of generating hypotheses regarding the nature of controls deployed by senior managers for their related and unrelated new products:

H2a: The nature of control will vary significantly between internally developed related and unrelated new products.

H2b: Formal controls for internally developed unrelated new products will be significantly tighter than those for related new products.

H2c: Informal controls for internally developed unrelated new products will be significantly looser than those for related new products.

\section{New Product Uniqueness}

New products can also be categorized as either "original" or "imitative". When a new product is considered original, it is essentially one which is new to the world. Original new products typically represent the first entry of a new product class or category (Bart, 1991). As such, original new products are significantly different in terms of product attributes and/or customer uses from all existing products (Bart, 1993a; Ettlie, Bridges \& O'Keefe, 1984). 
Imitative products, on the other hand, copy or build largely on the efforts of a competitor (Bart, 1993b). Such products work from known technologies, known market characteristics and known competitive information (Bart, 1993a).

Innovating under these two different circumstances would naturally seem to require its own unique control characteristics. Bart (1993a) found that original new products were managed significantly looser than imitative ones. He claimed that this occurred because original new products need looser overall control in order to encourage creativity and uniqueness within subordinate managers.

Likewise, both Marino (1982) and Kamm (1989) reached similar conclusions to Bart when they found that new products requiring high amounts of new ideas and creativity were best managed with loose controls. Aiken et al's (1980) finding, however, that loose organizational controls did not produce more original new products is inconsistent with Marino's and Kamm's assertions.

In contrast to original new products, Bart (1993a) found that imitative new products appeared to require significantly tighter levels of senior management control. Managers justified taking this approach on the grounds that imitative new products are, by their nature, easier to understand and, hence, create a context for senior managers to "add their brilliance".

Imitative new products, nevertheless, also present certain risks. On the one hand, a "me too product" is known to invite a potential financial and commercial disaster (Cooper, 1982). There is also the danger that in attempting to differentiate an imitative new product, subordinate managers will get carried away. Senior managers, thus, considered it their responsibility to make sure that neither of these events happened. 
The research investigating differences in organizational and control arrangements between imitative and original new products, however, is extremely sparse. Apart form the work by Bart, the prior literature is also generally limited to studies of single dimension control measures. Nevertheless, based on the directions established by the literature available, we developed the following hypotheses:

H3: Both the nature and degree of control will vary significantly between internally developed imitative and original new products.

H4: Original new products will be managed significantly more loosely than imitative new products.

\section{New Product Control and Performance}

Previous contingency theory research suggests that a firm's organizational choices make a difference in terms of performance (Lawrence \& Lorsch, 1967; Rumelt 1972; Lorsch \& Allen, 1973). Numerous researchers have attempted to extend this notion to the field of innovation. Most researchers contend today that innovation is best managed when the level of formal control exercised is "loose" and the level of informal control exercised is "tight" (Alpin \& Cosier, 1980, Burns \& Stalker, 1961; Galbraith \& Kazanjian, 1982; Thompson, 1965; Hage \& Aiken, 1970; Kimberly, 1981; Quinn, 1985; Wind, 1982; Bart, 1991, 1993a, 1993b).

Too few studies, unfortunately, have attempted simultaneously to classify new products according to different innovation attributes (or strategies), to identify the organizational arrangements for each directly and to measure their impact on different performance parameters. As a consequence, the relationship among new product strategy, managerial control and 
performance remains relatively unexamined.

Instead, most previous studies have tended to treat all new products and innovations as the same. Moreover, those studies that have considered the performance impact of selected control methods on firm innovativeness have tended to focus only on "new product output" as the performance measure. One's control choices, therefore, have been traditionally seen as either a potential aid or impediment to the amount or frequency of innovation. Few studies have considered the organizational control requirements associated with "successful new products" i.e. new products which have met or exceeded management's expectations. Yet, it is entirely possible that the control requirements necessary for encouraging a high volume of new products ("Let's get'em out the door!") are quite different from the controls necessary for ensuring that the new products launched are of high quality i.e. successful.

The research hypothesis we developed, therefore, were as follows:

H5a: The overall level of managerial control will, both collectively and for each of our four new product categories, vary significantly between "high output" and "low output" new product situations.

H5b: When new product output is "high", formal controls for internally developed new products will, both collectively and for each of our four new product categories, be significantly looser (or lower) than when new product output is "low".

H5c: When new product output is "high", informal controls for internally developed new products will, both collectively and for each of our four new product categories, be significantly tighter (or higher) than when new product output is "low". 
H6: The nature and degree of control will, both collectively and for each of our four new product categories, vary significantly between "successful" and "unsuccessful" new product situations.

Because we were not able to specify in advance the direction of any differences in formal or informal control practices with respect to new product success, no individual research hypotheses were developed.

\section{RESEARCH METHOD}

\section{Sample Selection and Size}

The current study involved in-depth interviews with 98 SBU managers. All of the SBU's were located within firms considered to be among the largest competitors in North America. All of the SBUs were engaged in various degrees of new product activities. SBU size ranged from approximately $\$ 100$ million to over $\$ 1$ billion.

While the method of sample selection (i.e. finding SBU managers willing to cooperate) restricts some of the claims that might be made about the representativeness of the findings, a review of selected operating and financial statistics could reveal no evidence of a response bias.

\section{Control Defimed}

While numerous definitions abound, most researchers agree that the primary purpose of control is to minimize idiosyncratic activities (Child, 1973; Klein, 1989; Lord \& Hanges, 1987; 
Tannenbaum, 1968). For the purposes of this research, control was operationalized along seven formal and seven informal dimensions. These dimensions were drawn directly from previous research which identified them as being associated with the concept of control (Bart, 1991, 1993a, 1993b; Child, 1973; Galbraith \& Kazanjian, 1986; Hage \& Aiken, 1967; Mintzberg, 1979; Ouchi, 1979, 1980; Tannenbaum, 1968).

The formal control dimensions selected were: the amount of formal rules and procedures; the subordinate's job definition; the tightness of a subordinate's budget; the amount of plan/budget detail supplied to SBU managers by subordinates; the amount of written instructions from SBU managers to subordinates; the frequency of subordinate reporting to SBU managers; and the SBU manager's reliance on other formal systems (e.g. MBO's, new product screening/evaluation models, etc.) to monitor and evaluate the progress of new products.

The informal organizational control dimensions selected included: the frequency of personal contact between a SBU manager and a subordinate; the SBU manager's frequency of contact with customers; the degree of subordinate latitude i.e. the degree to which SBU managers insist that subordinates adhere to company rules; the degree of decision making autonomy that subordinates are given by their SBU managers; the SBU manager's intolerance for failure; the amount of attention a SBU manager gives a subordinate; and the SBU manager's reliance on other informal procedures (e.g., MBWA, personal networks, informal meetings, etc.) to monitor and evaluate new products.

\section{New Products Defined}

There is a growing consensus among researchers to measure the newness of a product 
in terms relative to the innovating firm (Aiken \& Hage, 1979; Downs \& Mohr, 1976; Tushman \& Nadler, 1986; Kamm, 1987; Souder, 1987; Bart, 1991, 1993a, 1993b). This is because it is the firm's perception of newness that ultimately influences a SBU manager's behavior and his/her choices with respect to control. In keeping with this tradition, if a SBU manager in the current study considered a product as new, it was then treated as such the purposes of analysis.

\section{Identifying New Product Categories}

For the purposes of this study, two frequently cited dimensions were used to classify new products: familiarity to existing skills (related/unrelated); and degree of uniqueness (imitative/original). SBU managers were asked to categorize their new products along these lines.

\section{Data Collection}

Data on the strategy and control of new products within each firm were gathered by on site personal interviews. A questionnaire was developed in which SBU managers were asked, in the presence of the author, to rate the control they exercised over their subordinates in connection with randomly chosen new products that were under their jurisdiction. Each control variable was measured by asking SBU managers to indicate on a 10 point scale the degree to which a phrase described his/her perceived approach to controlling new products $(0$ to $4=$ "low"; 5 to $9=$ "high"). Where circumstances warranted, the SBU managers were asked to provide explanations for their responses.

Some SBU managers completed questionnaires for up to four subordinates reporting 
directly to him/her. Each subordinate manager had, in turn, at least one new product and one established product in his or her portfolio.

In total, data were obtained on SBU manager control practices as they applied to 148 subordinate managers managing 148 new products.

\section{Measuring New Product Performance}

New product performance was defined from the perspective of each firm and measured according to the SBU manager's perception of a subordinate manager's "new product frequency" (or output) and "new product success" (i.e. met or exceeded expectations) using a ten point scale (0 to 4 = "low"; 5 to 9 = "high").(See Bart, 1991, 1993a, 1993b; Cooper, 1982; Cooper, 1979; Souder, 1987). Absolute measures of performance were rejected since they tend to be arbitrary, cyclical, and influenced by the type of industry (Bart, 1991, 1993a, 1993b; Cooper, 1979, 1982; Souder, 1987).Perceptions, on the other hand, are what ultimately influence SBU manager behavior and their exercise of control.

\section{Data Analysis}

The SBU managers' control approach was independently measured for each new product situation. This was accomplished by randomly choosing the subunits that each SBU manager evaluated. Also, because the researcher administered the questionnaires personally, any dependency problems were further minimized by the way in which the questions were asked.

The SBU managers' responses were then compared and analyzed using independent sample t-tests for selected categories of new products - specifically, related versus unrelated new 
products; and imitative versus original new products.

\section{Overall Control Scores}

A method was needed to measure the overall degree of control dispensed by SBU managers under different conditions. Control scores were, therefore, individually calculated for each new product by summing the SBU managers' responses for each of the 14 control variables. (Scores measuring overall formal and overall informal control were also developed in a similar fashion by summing their respective control variables.). The differences in control scores for selected categories of new products were then analyzed statistically using independent sample t-tests.

\section{FINDINGS}

A comparison of the SBU managers' responses with respect to managing different types of new products is shown in Table 1.

\section{Related versus Unrelated New Products}

Hypothesis 1. When the overall control measures between related and new products were compared, the t-test results all confirmed that the null hypothesis could not be rejected at the 0.10 level of significance. There appeared to be no significant difference in the overall degree of control that SBU managers exercised between their related and unrelated new products. Hypothesis 1 could, therefore, not be supported. 
TABLE 1

NEW PRODUCT STRATEGIES \& CONTROL

\begin{tabular}{|c|c|c|c|c|}
\hline \multirow[b]{3}{*}{$\begin{array}{l}\text { NEW PRODUCT } \\
\text { CONTROL ITEMS }\end{array}$} & \multicolumn{4}{|c|}{ NEW PRODUCT STRATEGIES } \\
\hline & \multicolumn{2}{|c|}{ FAMILIARITY } & \multicolumn{2}{|c|}{ UNIQUENESS } \\
\hline & $\begin{array}{l}\text { Related (a) } \\
n=74\end{array}$ & $\begin{array}{l}\text { Unrelated (b) } \\
\quad n=74\end{array}$ & $\begin{array}{l}\text { Imitative (a) } \\
\quad n=66\end{array}$ & $\begin{array}{c}\text { Original (b) } \\
n=82\end{array}$ \\
\hline \multicolumn{5}{|l|}{ FORMAL VARIABLES } \\
\hline Rules \& procedures & \multicolumn{2}{|c|}{$<(.046)$} & \multicolumn{2}{|c|}{ n.s } \\
\hline Degree of subordinate job definition & \multicolumn{2}{|c|}{ n.s. } & \multicolumn{2}{|c|}{ n.s. } \\
\hline Tightness of budgets & \multicolumn{2}{|c|}{$<(.007)$} & \multicolumn{2}{|c|}{ n.s. } \\
\hline Amount of plan/budget detail & \multicolumn{2}{|c|}{ n.s. } & \multicolumn{2}{|c|}{ n.s. } \\
\hline Amount of written instruction & \multicolumn{2}{|c|}{ n.s. } & \multicolumn{2}{|c|}{$>(.002)$} \\
\hline Frequency of reporting & \multicolumn{2}{|c|}{$>(.0425)$} & \multicolumn{2}{|c|}{ n.s. } \\
\hline $\begin{array}{r}\text { Reliance on other formal systems and } \\
\text { procedures }\end{array}$ & \multicolumn{2}{|c|}{$<(.091)$} & \multicolumn{2}{|c|}{$>(.012)$} \\
\hline \multicolumn{5}{|l|}{ INFORMAL VARIABLES } \\
\hline Frequency of personal contact & \multicolumn{2}{|c|}{ n.s. } & \multicolumn{2}{|c|}{$>(.018)$} \\
\hline Frequency of customer contact & \multicolumn{2}{|c|}{ n.s. } & \multicolumn{2}{|c|}{$>(.033)$} \\
\hline Adherence to rules & \multicolumn{2}{|c|}{ n.s. } & \multicolumn{2}{|c|}{ n.s. } \\
\hline Degree of decision making autonomy & \multicolumn{2}{|c|}{ n.s. } & \multicolumn{2}{|c|}{$>(.000)$} \\
\hline Degree of intolerance for failure & \multicolumn{2}{|c|}{$<(.028)$} & \multicolumn{2}{|c|}{ n.s. } \\
\hline Amount of attention & \multicolumn{2}{|c|}{$>(.014)$} & \\
\hline Reliance onother informal procedures & \multicolumn{2}{|c|}{$>(.092)$} & \multicolumn{2}{|c|}{ n.s. } \\
\hline TOTAL FORMAL CONTROL SCORE & \multicolumn{2}{|c|}{ n.s. } & \multicolumn{2}{|c|}{$>(.017)$} \\
\hline TOTAL INFORMAL CONTROL SCORE & & & & \\
\hline TOTAL CONTROL SCORE & & $(*)$ & & \\
\hline
\end{tabular}

Legend: $(1)=$ Probability of one-tail $t$ test score; maximum $=(0.100)$

$>\quad=$ New products type (a) managed significantly 'tighter' than new products type (b)

$<\quad=$ New products type (a) managed significantly 'looser' than new products type (b)

* $\quad=$ two-tail t-test 
Hypothesis 2a. When the individual control measures between related and unrelated new products were examined, there appeared to be considerable and significant diversity in the nature of control. Significant differences in control were obtained on seven of the fourteen control measures. Thus, substantial evidence was obtained in support of Hypothesis 2.

Hypotheses $2 \mathbf{b}$ and 2c. Table 1 shows that three of our seven formal control measures were found to significantly tighter than those used by SBU managers for their related new products. (One formal control, "frequency of formal reporting, was found to be significantly looser.) This would indicate that moderate evidence exists in favour of Hypothesis $2 \mathrm{~b}$.

However, informal controls for unrelated new products were found to be significantly looser than those for related new products in only two of our seven informal measures. Thus, while we can still reject the null hypothesis, the support for Hypothesis $2 \mathrm{c}$ appears to be very small and limited.

\section{Imitative versus Original New Products}

Hypothesis 3. Again, from Table 1, it appears that both the nature and degree of SBU manager control differ between imitative and original new products. Significant differences in control were found in six of the fourteen control measures. In addition, significant differences in the level/degree of SBU manager control was found in the overall "formal control score" and the "total control score". Thus, it was concluded that strong evidence was obtained in support of Hypothesis 3.

Hypothesis 4. Whenever significant differences in SBU manager control were calculated, original new products were always found to be managed more loosely than imitative new 
products. The evidence supporting Hypothesis 4 is, thus, both substantial and profound.

\section{New Product Control and Performance}

Hypotheses 5a. Table 2 presents the results of our analysis concerning the nature and degree of control on new product output. No significant differences in control (between high and low new product output situations) were found in any of our total (or overall) measures of control - either when all new product cases were considered collectively or when different categories of new products were considered individually. Thus, hypothesis 5 a could not be supported.

Hypothesis 5b. The results in Table 2 also show that formal controls for managing high new product output circumstances were, for the most part, significantly looser than those used in low new product output conditions. Collectively, significant differences in SBU manager control were obtained on both the overall formal control score as well as on 4 of the 7 individual formal control dimensions.

When we extended the analysis of formal controls over to our four different categories of new products, however, the evidence in support of Hypothesis $5 \mathrm{~b}$ - while still present - was less impressive. The unrelated new product category offered the strongest support. It was also the only new product category to show a significant difference, as predicted, in the overall degree of formal control. Related and original new products, on the other hand, provided the weakest evidence while imitative new products exhibited results opposite to those expected.

Hypothesis 5c. As expected, informal controls were found to be significantly tighter in "high" (as compared to "low") new product output situations. However, collectively, these 
TABLE 2

NEW PRODUCT STRATEGY, NEW PRODUCT FREQUENCY \& CONTROL

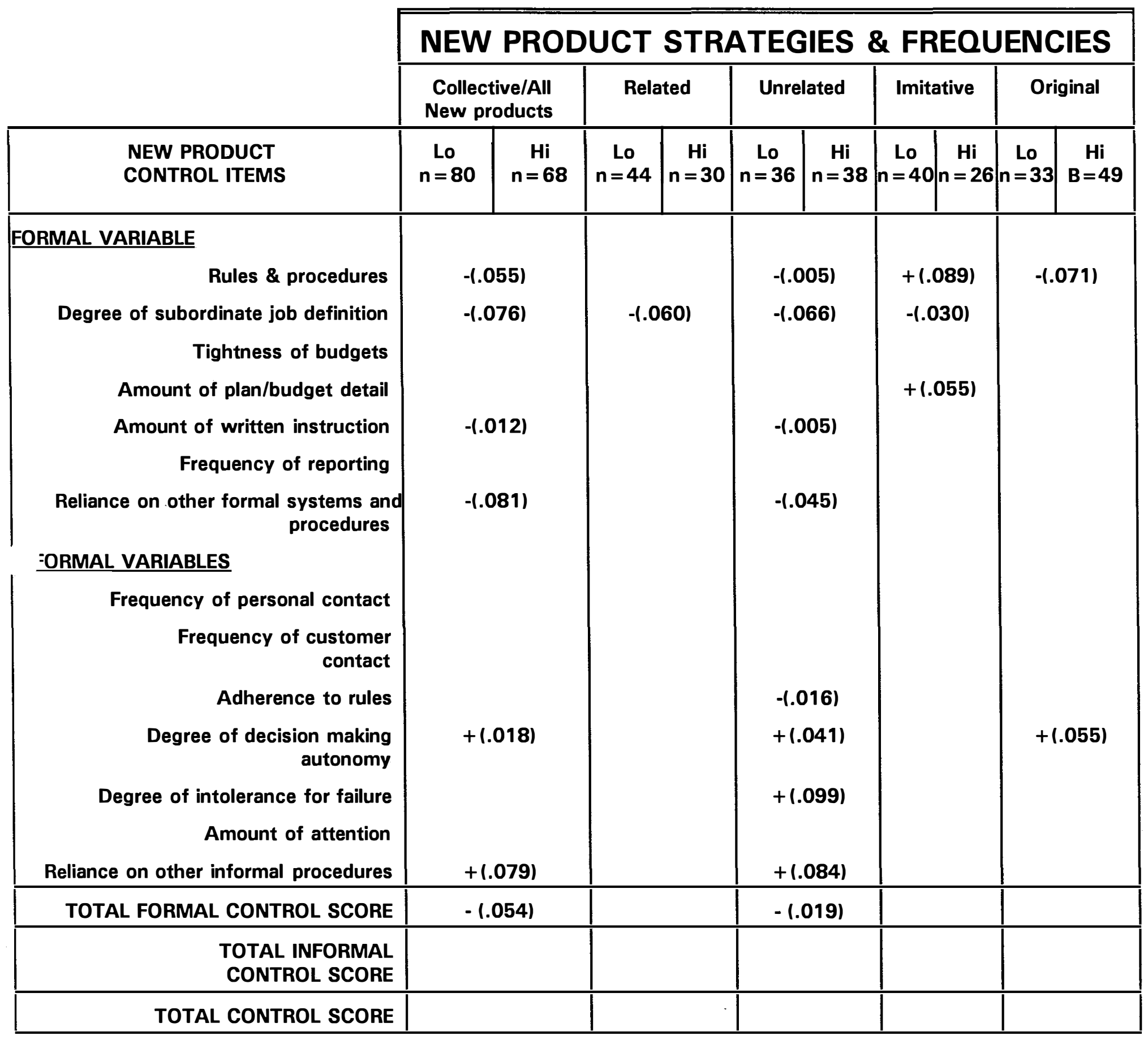

Legend: $\quad+=$ New products (Hi output category) controlled significantly 'tighter' than new products (Lo output categoryl

- = New products (Hi output category) controlled significantly 'looser' than new products (Lo output categoryl

Lo = Low New Product Frequency

$\mathrm{Hi}=$ High New Product Frequency

( ) = Probability of one-tail t-test score; maximum $=0.10$ 
tighter controls were found to exist in only two areas: degree of decision making autonomy and reliance on other informal procedures.

Individually, the strongest support for Hypothesis $5 c$ existed, once again, in the unrelated new products category. In the other three new product categories, there were no significant differences in informal controls between high and low new product situations - with one exception i.e., degree of decision making autonomy in original new products. Conveniently, this difference occurred in the manner predicted. Support for Hypothesis 5c, therefore, appears to be somewhat limited.

Hypothesis 6. Table 3 presents the results of our analysis concerning the nature and degree of control with respect to new product "success". The results indicate that both the nature and degree of control varied significantly between having new products which are frequently successful and those which are not. Collectively, significant differences in SBU manager control practices were obtained on 5 of the 14 individual control dimension measures. Significant differences in two of the overall control measures (i.e. formal and total) were also obtained.

Interestingly, all of the significantly different controls for managing highly successful new products (both formal and informal) were observed to be tighter than those used with "low success" new products - including the overall control measures.

When we extended our analysis over to the four different categories of new products, the evidence in support of Hypothesis 6 appeared to remain fairly strong. Table 3 shows that significant differences, within individual control dimensions, existed between high and low new product success in all new product categories. It is noteworthy that the observed significant differences within different product categories were consistently "tight" - much as thery were 


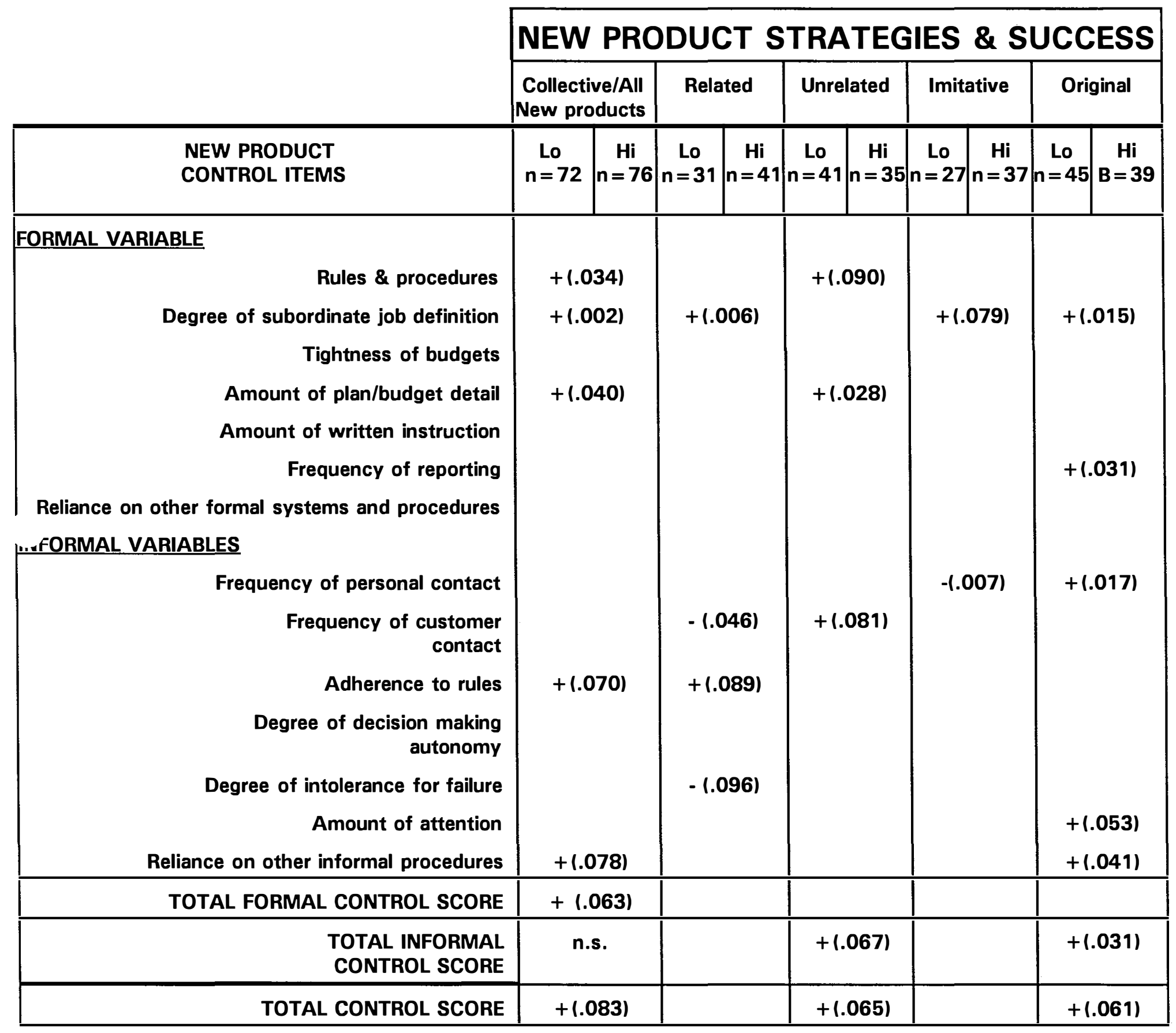

Legend: $\quad+\quad=$ New products (Hi success category) controlled significantly 'tighter' than new products (Lo success category)

- $\quad=$ New products (Hi success category) controlled significantly 'looser' than new products (Lo success categoryl

Lo $=$ Low New Product Frequency

( ) = Probability of two-tail t-test score; maximum $=0.10$

$\mathrm{Hi}=$ High New Product Frequency 
when measured collectively. The informal controls, however, were not as homogeneous. They represented instead a collection of significantly looser and tighter controls. Nevertheless, significant differences in the total/overall degree of control were also obtained in two of the four new product categories i.e. unrelated and original.

The support for Hypothesis 6, therefore, appears to be substantial.

\section{DISCUSSION AND CONCLUSIONS}

The central propositions of this study were that (a) SBU manager control varies with different types of new products; and (b) the control an SBU manager uses makes a difference in terms of firm performance. For the most part, the findings presented in this article tend to support this contingency view of the relationship among new product strategy, managerial control and performance.

While Hypothesis 1 was not confirmed, Hypothesis $2 \mathrm{a}$ was. There were no significant differences noted in any of the overall measures of control (formal/informal/total) between related and unrelated new products. However, there was diversity in the nature and manner with which SBU managers exercised control on specific control dimensions. SBU managers used a mixture of tightness and looseness when deploying individual controls (Bart, 1991, 1993a, 1993b). But because of this heterogeneity in their approach to control, the "summed" overall control scores tended to cancel-out any aggregate differences. This latter observation, thus, serves to underscore the potential danger that often exists when using "overall measures". The 
aggregate results obtained may mask the differences that are of real interest to the researcher.

Hypotheses $2 b$ and $2 c$, however, were confirmed. It is especially noteworthy that the results obtained here are consistent with the findings from the acquisition/diversification literature. Unrelated new products are (as are unrelated divisions) unfamiliar and foreign entities to most SBU senior managers. Consequently, an SBU manager's approach to controlling such new products, as shown in Table 1, tends to be much more impersonal than with related new products and involves (i) setting out company rules more; (ii) controlling budgets more tightly; (iii) relying more on other formal mechanisms to reduce inefficiencies (e.g. new product screening models); and (iv) communicating a greater intolerance for failure.

Related new products, on the other hand, are something that senior SBU managers understand. As a result, they give them more personal attention than unrelated new products and they use other informal procedures more - both to monitor and evaluate progress and to increase the effects of synergy. The present findings, therefore, suggest that the diversification/acquisition literature may be a fruitful source for both theory building and practical suggestions when the innovation literature (as was the case here) is silent.

It is also important to note that previous studies have attempted to argue positions opposite to those obtained here for Hypotheses $2 \mathrm{a}, 2 \mathrm{~b}$ and $2 \mathrm{c}$ - i.e. that related new products are loosely controlled and unrelated new products are controlled tightly. Such observations now appear to be due, however, to such factors as: small (pilot) sample sizes, single dimension control measures and the failure to compare different new product types directly.

Hypotheses 3 and 4 were also confirmed. Both the nature and degree of control was found to vary between imitative and original new products. Whenever significant differences 
were obtained, original new products were always found to be managed more loosely than imitative ones.

The implication of this finding, however, is particularly striking. SBU managers seeking to encourage original new products need to provide considerable slack to their subordinates (in the form of both reduced formal and informal controls) in order to get maximum creativity. In contrast, imitative new products appear to require significant measures of tight control (see Table 1). (Once again, this tight control occurs because SBU managers find imitative new products much easier to understand and because there must be vigilance to avoid creating "me-too" type products.) Other categories of new products, as well, seem to have at least some forms of tight control. How, then, do SBU senior managers control their original new products given their low levels of formal and informal control?

First, it should be noted that low control does not mean no control. In all instances of measuring control over original products, there was some minimum level of control always present. More importantly, however, it appears that the control mechanism which senior managers ultimately rely upon is internal to the subordinate managers themselves. Specifically, the "thrill of creating something totally new and original" is apparently what drives and motivates subordinate managers to stick with their task and achieve SBU objectives and/or project "specs". Many senior mangers remarked that this "internal control" was stronger than any formal or informal controls that they could devise. This aspect of control should, therefore, be investigated directly and more intensively in any future studies.

Hypotheses 5a, 5b and 5c, however, received mixed results. While there were few differences in the overall control measures between high and low new product situations, 
individual formal controls were generally looser and individual informal controls were somewhat tighter for high output new product situations than they were for low new product output conditions. These results also tended to carry over to our analysis of the different new product categories. Thus, the nature of SBU manager control appears to make a difference in terms of an organization's new product frequency or output.

Two interesting observations flow from these results, however. The first is that a review of the data in Table 3 indicates that there were no significant differences in informal control within most new product categories. Yet, our review of actual control scores reveals that the level of informal control exercised over different categories of new products was quite high. What this means is that most managers implicitly understand that the level of control that they need to exercise for high quantities of new products is fairly tight. Where most managers appear to be erring in their quest for more new products, however, is in their level of formal controls which are not loose enough.

Additionally, the findings with respect to Hypotheses 5a, 5b, and 5c suggest an intriguing interpretation when combined with our earlier results. It has been recently stated that in order to have large quantities of new products, formal controls should be loose and informal controls somewhat tight. Yet, earlier it was observed that (a) unrelated new products appear to require formal controls which are fairly tight (relative to related new products); and (b) original new products appear to require informal controls which are fairly loose (relative to imitative ones). How then should one go about reconciling these apparent contradictions in control strategy or philosophy? We believe that the solution lies in taking the following perspective. The findings pertaining to high new product output (i.e. loose/formal - tight/informal) should be treated as 
a sort of general principal. Having done this, an SBU manager must then overlay the findings obtained here regarding different strategic categories in order to fine-tune his/her control approach. One such application follows:

$\begin{array}{lccc}\text { CONTROL } & \begin{array}{c}\text { OVERALL CONTROL RELATED CONTROL } \\ \text { SCORES }\end{array} & \begin{array}{c}\text { UNRELATED CONTROL } \\ \text { SCORE }\end{array} \\ \text { TYPES } & \text { SCORE } & \\ \text { Formal } & -7 & -5 & -2 \\ \text { Informal } & +7 & +4 & +3\end{array}$

In this simplified example, the formal control scores are always less than the informal control scores. In addition, the formal control score for the unrelated product is much tighter (or lower) than for the related's and its informal control score is, in turn, somewhat looser.

Hypothesis 6, our final hypothesis, was also confirmed. In many ways, this is the most interesting finding from the current study. It suggests that in order to have high quantities of successful new products, all managerial controls (both formal and informal) should be tight. At first glance, this appears to fly in the face of our earlier findings concerning high/low new product output (Hypothesis 5b). However, on reflection, the findings appear to make good sense.

If a firm is struggling to get more new products out its doors, one of the easiest ways of accomplishing this is to remove or reduce many of the formal controls which slow down innovation - especially the amount of written instructions, job definition, rules and procedures, etc. Yet, while the quantity of new products should increase, there is no guarantee of commercial success.

The findings in Table 3 imply, however, that to have high quantities of successful new products, one should increase the level of formal control - particularly with respect to written 
rules and procedures, the subordinate's job definition and the amount of plan/budget detail. And the reasons for this are again fairly straightforward, even obvious. Specifically, one cannot have a subordinate spearheading a new product project if $\mathrm{s} / \mathrm{he}$ does not know what the rules of the game are. Moreover, when formal controls are too loose, there is the danger of a subordinate losing his/her focus - especially in large organizations where senior managers cannot always be relied upon for coaching, consultation and clarification. Perhaps this is why so many new products are ultimately judged to be failures (Cooper, 1982). Subordinates and their new products are being judged on objectives and performance criteria which are not fully developed until after the project is launched. These unfortunate subordinates are, thus, "shooting at a moving target" in which their failure is pre-ordained.

Success with new products, however, requires good planning and good planning means having a clear understanding about what is expected in terms of a new product's technical performance and future financial return. But good planning takes time which, in turn, may slow down the rate of new product output. Thus, the current North American obsession with increasing new product output by "reducing new product cycle time" may come with a price: more commercial bombs! Interestingly, there is some emerging and tentative evidence that increasing the formal controls over new products (specifically in the form of new product screening techniques) not only increases their rate of commercial success but also improves their speed to market (Bart, 1994; Cooper, 1990). More research in this area, in particular, is clearly warranted. 


\section{SOME FINAL THOUGHTS}

The results presented in this study support the notion that individual new product strategies may impose unique control requirements on an organization's managers as they attempt to achieve various ends. In other words, different strategies require different structures. Consequently, SBU managers should not treat their approach to controlling new products with abandon. The nature and degree of SBU manager control are related both to the type of new product and to various performance outcomes. SBU managers, therefore, need to consider carefully their approach to control when managing any new product situation. 


\section{REFERENCES}

Aiken, M. Bacharach, S. and French, J. "Organization structure, work process, and proposal making in administrative bureaucracies," Academy of Management Journal, 23, 1980, pp. 63152.

Aiken, M. and Hage, J. "The organic organization and innovation." in: Readings on dimensions of organizations. M. Zey-Ferrell (ed.). Santa Monica, CA: Goodyear, 1979, pp. 263-279.

Alpin, J.C. and Cosier, R.A. "Managing creative and maintenance organizations." The Business Quarterly, Spring 1980, pp. 55-63

Bart, C.K. "Product strategy and formal structure." Strategic Management Journal, Vol. 7, 1986, pp. 293-312.

Bart, C.K. "New venture units: Use them wisely to manage innovation," Sloan Management Review, Vol. 29, No. 4, 1988, pp. 35-44.

Bart, C.K. "Controlling new products: A presidential perspective." Journal of Product Innovation Management, Vol. 8, 1991, pp. 4- 17.

Bart, C. K. "General managers control new and existing products differently," Journal of Business Venturing, Vol. 8, 4, July, 1993a, pp. 341-361.

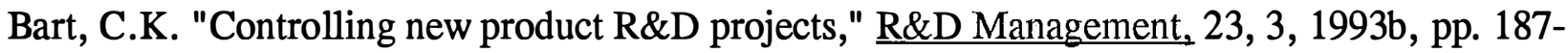
197.

Bart, C.K. "Gagging on chaos", Business Horizons. Sept-Oct, 1994, pp. 26-36.

Baysinger, B. and Hoskisson, R.E. "Diversification strategy and R\&D intensity in multiproduct firms." Academy of Management Journal, Vol. 32, No. 2, 1989, pp. 310-332.

Burns, T. and Stalker, G.M. The management of innovation. London: Tavistock,1961.

Chandler, A.D. Strategy and structure: Chapters in the history of the industrial enterprise. Cambridge: MIT Press, 1962.

Child, J. "Strategies of control and organizational behavior." Administrative Science Quarterly, March 1973, pp. 1-17.

Cooper, R.G. "Stage-gate systems: A new tool for managing new products." Business Horizons, Vol. 33, No. 3, May-June, 1990, pp. 44 - 54. 
Cooper, R.G. "New product success in industrial firms." Industrial Marketing Management, Vol. 11, No. 3, 1982, pp. 215-223.

Cooper, R.G., "The dimensions of industrial new product success and failure." Journal of Marketing, Vol. 43, No. 3, Summer 1979, pp. 93-103.

Downs, W., Jr. and Mohr, B. "Conceptual issues in the study of innovation." Administrative Science Quarterly, Vol. 21, 1976, pp. 700-714.

Dundas, K. and Richardson, P. "Implementing the unrelated product strategy," Strategic Management Journal, 3, 1882, 287-301.

Ettlie, J.E., Bridges, W.P. and O'Keefe, R.D. "Organizational strategy and structural differences for radical versus incremental innovation." Management Science, Vol. 30, 1984, pp. $682-95$.

Evan, W.M. Organization theory: Structures, systems and environments. New York: Wiley Inter-science, 1976.

Galbraith, J.R. and Kazanjian, R. K. Strategy implementation: Structure, systems and process, Second edition. St. Paul: West Publishing, 1986

Gupta, A. "SBU strategies, corporate-sbu relations and SBU effectiveness in strategy implementation," Academy of Management Journal, 30, 1987, pp. 477-500.

Hage, J. and Aiken, M. "Program change and organizational properties: A comparative analysis," American Journal of Sociology, 72:503-19, 1967.

Hill, C.W.L and Hoskisson, R.E. "Strategy and structure in the multiproduct firm." Academy of Management Review, Vol. 12, No. 2, 1987, pp. 331-341.

Hitt, M.A., Hoskisson, R.E., and Ireland, R.D. "Mergers and aquisitions and managerial commitment to innovation in M-form firms." Strategic Management Journal, Vol. 11, 1990, pp. 29-47.

Hoskisson, R.E. "Multidivisional structure and performance: The contingency of diversification strategy." Academy of Management Journal, Vol. 30, No. 4, 1987, pp. 625-644.

Hoskisson, R.E. and Hitt, M.A. "Strategic control systems and relative R\&D investment in large multiproduct firms." Strategic Management Journal, Vol. 9, pp. 605-621, 1988.

Kamm, J.B. An integrative approach to managing innovation. Lexington, Ma.: Lexington Books, 1987. 
Kidder, T. The soul of a new machine. New York: Pann, 1984.

Kimberly, J.R. (1981). "Managerial Innovation". In P.C. Nystrom and W.H. Starbuck (eds.), Handbook of Organization Design. Vol. 1. Adapting Organizations to their Environments (pp. 84-104). New York: Oxford University Press.

Klavans, R., Shanley, M. and Evan, W. "The management of internal corporate ventures: Entrepreneurship and innovation." The Columbia Journal of World Business, Spring 1985, pp. 21-27.

Klein, H.J. "An integrated control theory model of work motivation." Academy of Management Review, Vol. 14, No. 2, 1989, pp. 150-172.

Lawrence, P. and Lorsch, J.W. Organization and environment: Managing differentiation and integration. Graduate School of Business, Harvard University, Boston, Mass., 1967.

Lord, R.G. and Hanges, P.J. "A control systems model of organizational motivation: Theoretical development and applied implications." Behavioral Science, Vol. 32, 1987, pp. 161-178.

Lorsch, J. and Allen, S. 1973, Managing diversity and interdependence. Boston: Division of Research, Graduate School of Business Administration, Harvard University.

Marino, K. E. "Structural correlates of affirmative action compliance," Journal of Management, 8, 1982, pp. 75-93.

Miller, D. and Friesen, P.H. Organizations: A quantum view. Englewood Cliffs: Prentice Hall, 1984.

Mintzberg, H. The structure of organization. Englewood Cliffs: Prentice Hall, 1979.

Normann, R. "Organizational innovativeness: Product variation and reorientation," Administrative Science Quarterly, June, 1971, pp. 203-15.

Ouchi, W. G. "A conceptual framework for the design of organizational control mechanisms." Management Science, Vol. 25, No. 9, 1979, pp. 833-848.

Ouchi, W.G. "Markets, bureaucracies and clans." Administrative Science Quarterly, Vol. 25, March 1980, pp. 129-141.

Peters, T. \& Waterman, R. In search of excellence. New York, NY: Harper Row, 1983.

Quinn, J.B. "Managing innovation: controlled chaos." Harvard Business Review. May-June, 1985, pp. 2 - 21. 
Rumelt, R.P. Strategy, structure and economic performance. Graduate School of Business Administration, Harvard University, Boston, MA: 1974.

Souder, W.E. Managing new product innovations. Lexington, Ma.: Lexington Books, 1987.

Tannenbaum, A. Control in organizations. New York, NY: McGraw Hill,1968.

Thompson, V.A. "Bureaucracy and innovation." Administrative Science Quarterly, Vol. 10, June, 1965, pp. 1-20.

Teece, D. "Towards an economic theory of the multiproduct firm," Journal of Economic Behavior and Organization, 3, 1982, pp.39-63.

Tushman, M. and Nadler, D. "Organizing for innovation." California Management Review, Vol. 28, Spring 1986, pp. 74-92.

Williamson, O.E. "Emergence of the visible hand: Implications for industrial organizations." In Chandler, A.D. and Daems, H. (eds.), Managerial hierarchies. Cambridge, Mass: Harvard University Press, 1980, pp. 182-202.

Williamson, O.E. Markets and hierarchies: Analysis and antitrust implications, Macmillan Free Press, New York, 1975.

Wind, Y.J. Product policy: Concepts, methods and strategy. Reading, Mass.: Addison Wesley, 1982. 


\section{INNOVATION RESEARCH WORKING GROUP WORKING PAPER SERIES}

1. R.G. Cooper and E.J. K1einschmidt, "How the New Product Impacts on Success and Failure in the Chemical Industry", February, 1992.

2. R.G. Cooper and E.J. Kleinschmidt, "Major New Products: What Distinguishes the Winners in the Chemical Industry", February, 1992.

3. J. Miltenburg, "On the Equivalence of JIT and MRP as Technologies for Reducing Wastes in Manufacturing, March, 1992.

4. J.B. Kim, I. Krinsky and J. Lee, "Valuation of Initial Public Offerings: Evidence from Korea", February, 1992.

5. M. Basadur and S. Robinson, "The New Creative Thinking Ski1ls Needed for Total Quality Management to Become Fact, Not Just Philosophy", Apri1, 1992.

6. S. Edgett and S. Parkinson, "The Development of New Services Distinguishing Between Success and Failure", Apri1, 1992.

7. A.R. Montazemi and K.M. Gupta, "Planning and Development of Information Systems Towards Strategic Advantage of a Firm", Apri1, 1992.

8. A.R. Montazemi, "Reducing the Complexity of MIS Innovation Through Hypermedia and Expert Systems", May, 1992.

9. M. Basadur and Bruce Paton, "Creativity Boosts Profits in Recessionary Times - Broadening the Playing Field", June, 1992.

10. Robert G. Cooper and Elko Kleinschmidt, "Stage-Gate Systems for Product Innovation: Rationale and Results", June, 1992.

11. S.A.W. Drew, "The Strategic Management of Innovation in the Financial Services Industry: An Empirical Study", July, 1992.

12. M. Shehata and M.E. Ibrahim, "The Impact of Tax Policies on Firms' R \& D Spending Behavior: The Case of R \& D Tax Credit", July, 1992.

13. Willi $\mathrm{H}$. Wiesner, "Development Interview Technology: Implications for Innovative Organizations", July, 1992.

14. Isik U. Zeytinoglu. "Technological Innovation and the Creation of a New Type of Employment: Telework", August, 1992

15. John W. Medcof, "An Integrated Model for Teaching the Management of Innovation in the Introduction to Organizational Behaviour Course", October, 1992. 
16. Min Basadur, "The Why-What's Stopping Analysis: A New Methodology for Formulating I11-Structured Problems", October, 1992.

17. Stephen A.W. Drew, "Strategy, Innovation and Organizational Learning an Integrative Framework, Case Histories and Directions for Research", November, 1992.

18. Stephen A.W. Drew, "Innovation and Strategy in Financial Services", November, 1992.

19. Scott Edgett, "New Product Development Practices for Retail Financial Services", November, 1992.

20. Robert G. Cooper and Elko J. Kleinschmidt, "New Product Winners and Losers: The Relative Importance of Success Factors - Perception vs. Reality", November, 1992.

21. Robert G. Cooper and Elko J. Kleinschmidt, "A New Product Success Factors Model: An Empirical Validation", November, 1992.

22. Robert G. Cooper \& Elko J. Kleinschmidt, "Stage Gate Systems: A Game Plan for New Product Success", November, 1992.

23. Min Basadur, "Optimal Ideation-Evaluation Ratios", March, 1993.

24. Christopher K. Bart, "Gagging on Chaos", March, 1993.

25. Yufei Yuan, "The Role of Information Technology in Business Innovation", July, 1993.

26. Isik Urla Zeytinoglu, "Innovation in Employment: A Telework Experiment in Ontario", July, 1993.

27. John Miltenburg and David Sparling, "Managing and Reducing Total Cycle Time: Moles and Analysis", August, 1993.

28. R.G. Cooper, C.J. Easingwood, S. Edgett, E.J. Kleinschmidt and C. Storey, "What Distinguishes the Top Performers in Financial Services", September, 1993.

29. B.E. Lynn, "Innovation and Accounting Research", September, 1993.

30. Min Basadur and Peter Hausdorf, "Measuring Additional Divergent Thinking Attitudes Related to Creative Problem Solving and Innovation Management", November, 1993.

31. R.G. Cooper and E.J. Kleinschmidt, "Determinants of Time Efficiency in Product Development", December, 1993

32. Christopher K. Bart, "Back to the Future: Timeless Lessons for Organizational Success", February, 1994. 
33. Ken R. Deal and Scott J. Edgett, "Determining Success Criteria for New Financial Products; A Comparative Analysis of CART, Logit and Discriminant Analysis", February, 1995.

34. Christopher K. Bart and Mark C. Baetz, "Does Mission Matter?", February, 1995. 